\title{
HUBUNGAN PENGETAHUAN, SIKAP, DAN TINDAKAN BIDAN TERHADAP KEPATUHAN PELAKSANAAN ASUHAN PERSALINAN KALA II DI RUMAH BERSALIN DAN BALAI PENGOBATAN UMMI PALEMBANG TAHUN 2018
}

\author{
Junawalia Mayang Sari \\ D III Akademi Kebidanan Pondok Pesantren Assanadiyah Palembang \\ Jl. Banten 6 Kelurahan 16 Ulu Kecamatan Seberang Ulu II Palembang \\ Email : juna02776@gmail.com
}

\begin{abstract}
Abstrak
Bidan merupakan salah satu tenaga kesehatan yang memiliki posisi penting dan strategi terutama dalam penurunan Angka Kematian Ibu (AKI) dan Angka Kesakitan dan Kematian Bayi (AKB), bidan memberikan pelayanan yang berkesinambungan yang berdasarkan dengan pengetahuan dan standar kesehatan yang dimiliki dan paripurna, berfokus pada aspek pencegahan, promosi dengan berlandaskan kemitraan dan pemberdayaan masyarakat bersama-sama dengan tenaga kesehatan lainnya untuk senantiasa siap melayani siapa saja yang membutuhkannya, kapan dan dimanapun berada (Kepmenkes RI, 2007). Berdasarkan hasil uji statistic T-Independent didapatkan pada pengetahuan bidan yaitu: $P=0,000(p \leq \alpha)$, pada sikap bidan yaitu: $P=0,000(p \leq \alpha)$ dan pada tindakan bidan yaitu: $P=0,000(p \leq \alpha)$ yang berarti ada hubungan yang bermakna dan signifikan antara pengetahuan, sikap dan tindakan bidan terhadap kepatuhan dalam penatalaksanaan asuhan persalinan kala II. Diharapkan rumah bersalin UMMI dan instalasi lain dapat meningkatkan standar asuhan kebidan khususnya persalinan dengan cara mengikuti pelatihan kebidanan serta meningkatkan kemampuan agar tenaga kesehatan, khususnya bidan dapat menciptakan keefektifan pelayanan dan asuhan yang berkualitas dalam membimbing pasien.
\end{abstract}

Kata kunci : Standar Asuhan Persalinan, Standar penatalaksanaan kala II

\begin{abstract}
Midwifes are one of the health workers who have an important position and play an important role, especially in reducing maternal mortality rate (MMR) and infant mortality rate (IMR). Midwifes provide ongoing services based on latest information and health standards that are available. With focus on the aspect of prevention, promotion based on partnerships and community empowerment together with other health workers to always be ready to serve anyone who needs it, whenever and wherever they are (Kepmenkes RI, 2007). Based on the results of the T-Independent statistical test found on the knowledge of midwives, namely: $P=0,000(p \leq \alpha)$, on the attitude of midwives namely: $P=$ $0,000(p \leq \alpha)$ and on the midwife's actions namely: $P=0,000(p \leq \alpha)$ means there is a meaningful and significant relationship between knowledge, the attitude and actions of the midwife towards compliance in the management of the second stage of childbirth care. It is expected that UMMI's maternity home and other measurements can improve the standard of care, especially childbirth by attending midwifery training and increasing the ability for health workers and midwives to provide the quality of services and effective care in guiding patients.
\end{abstract}

Kata kunci : The standard of care, The second stage of childbirth care 


\section{PENDAHULUAN}

Di era globalisasi yang menuntut tersedianya sumber daya manusia profesional dalam memberikan pelayanan kesehatan kepada masyarakat. Profesionalisme terkait erat dengan kompetensi yang harus dimiliki oleh seorang profesional. Wilkerson (2002) yang disitasi oleh Suryadi (2009) menyatakan bahwa kompetensi profesional adalah suatu kebiasaan dan diterapkan dengan bijak dengan memperhatikan komunikasi, pengetahuan, keterampilan teknikal, alasan klinikal, emosi, nilai, dan refleksi dalam praktik sehari-hari untuk memperbaiki kesehatan individu, keluarga dan masyarakat. Sikap profesional bidan tidak terlepas dari harapan masyarakat terhadap profil seorang bidan.

Survey tentang kinerja bidan (Tim IBI \& AIPKIND, 2010) melalui pendekatan kualitatif menunjukkan bahwa pada intinya masyarakat mengharapkan bidan yang ramah, terampil dan tanggap dibidangnya. Mencermati harapan masyarakat tersebut, sudah selayaknya organisasi profesi dan asosiasi institusi pendidikan kebidanan menyusun suatu standar kompetensi bidan yang dapat digunakan sebagai acuan dalam penyelenggaraan pendidikan kebidanan, agar lulusan yang dihasilkan dapat memberikan pelayanan kebidanan berkualitas. Standar kompetensi bidan ini disusun berdasarkan body of knowledge, filosofi dan paradigma pelayanan kebidanan dengan mengacu pada Permenkes No. 369/ Menkes/SK/III/2007, tentang Standar Profesi Bidan, Permenkes nomor: 161/Menkes/PER/I/2010 tentang registrasi tenaga kesehatan dan Permenkes nomor: 1464/ Menkes/Per/X/2010 tentang izin dan penyelenggaraan praktik bidan.

Perilaku kesehatan adalah suatu respons seseorang atau organisme terhadap stimulus atau objek yang berkaitan dengan sakit dan penyakit, sistem pelayanan kesehatan, makanan dan minuman serta lingkungan (Notoatmodjo, 2009).
Benjamin Bloom seorang psikolog pendidikan, membedakan adanya tiga bidang perilaku, yakni kognitif, afektif, dan psikomotor. Kemudian dalam perkembangannya, perilaku diklasifikasikan oleh Bloom dibagi menjadi tiga tingkat yaitu ; Pengetahuan (knowledge), Sikap (attitude), Tindakan atau praktik (practice).

Menurut Becker (Wikipedia bahasa Indonesia, ensiklopedia bebas) Konsep perilaku sehat ini merupakan pengembangan dari konsep perilaku yang dikembangkan Bloom. Becker menguraikan perilaku kesehatan menjadi tiga domain, yakni pengetahuan kesehatan (health knowledge), sikap terhadap kesehatan (health attitude) dan praktik kesehatan (health practice). Hal ini berguna untuk mengukur seberapa besar tingkat perilaku kesehatan individu yang menjadi unit analisis penelitian.

Pengetahuan tentang kesehatan mencakup apa yang diketahui oleh seseorang terhadap cara-cara memelihara kesehatan, seperti pengetahuan tentang penyakit menular, pengetahuan tentang faktor-faktor terkait yang mempengaruhi kesehatan, pengetahuan tentang fasilitas pelayanan kesehatan, dan pengetahuan untuk menghindari kecelakaan. Berdasarkan penelitian yang dilakukan Bart (1994) dapat dikatakan bahwa perilaku yang dilakukan atas dasar pengetahuan akan lebih bertahan dari pada perilaku yang tidak didasari oleh pengetahuan. Jadi pengetahuan sangat dibutuhkan agar masyarakat dapat mengetahui mengapa mereka harus melakukan suatu tindakan sehingga perilaku masyarakat dapat lebih mudah untuk diubah kearah yang lebih baik.

Sikap terhadap kesehatan adalah pendapat atau penilaian seseorang terhadap hal-hal yang berkaitan dengan pemeliharaan kesehatan, seperti sikap terhadap penyakit menular dan tidak menular, sikap terhadap faktor-faktor yang terkait dan atau memengaruhi kesehatan, 
sikap tentang fasilitas pelayanan kesehatan, dan sikap untuk menghindari kecelakaan. Lou Holtz berpendapat "Kemampuan adalah apa yang anda mampu lakukan. Motivasi menentukan apa yang anda lakukan. Sikap menentukan seberapa baik Anda melakukannya". Funmi WaleAdegbite berpendapat Sukses adalah $80 \%$ sikap dan $20 \%$ bakat. Harry F. Banks pendapat Untuk sukses adalah, sikap sama sama pentingnya dengan kemampuan. Sikap adalah suatu bentuk evaluasi / reaksi terhadap suatu obyek, memihak / tidak memihak yang merupakan keteraturan tertentu dalam hal perasaan (afeksi), pemikiran (kognisi) dan predisposisi tindakan (konasi) seseorang terhadap suatu aspek di lingkungan sekitarnya (Saifudin A, 2005).

Perilaku/Praktek kesehatan (Perilaku akan tindakan kesehatan) untuk hidup sehat adalah semua kegiatan atau aktivitas orang dalam rangka memelihara kesehatan, seperti tindakan terhadap penyakit menular dan tidak menular, tindakan terhadap faktor-faktor yang terkait dan atau memengaruhi kesehatan, tindakan tentang fasilitas pelayanan kesehatan, dan tindakan untuk menghindari kecelakaan. Tindakan merupakan hal tertinggi dimana didalamnya terkandung unsur aktivitas, perbuatan dan pergerakan tubuh, namun sesungguhnya tindakan adalah skala kematangan seseorang dalam mencapai tujuan tertentu.

Persalinan membutuhkan usaha total ibu secara fisik dan emosional, karena itu dukungan moril dan upaya untuk menimbulkan rasa nyaman bagi ibu bersalin sangatlah penting. Ibu mungkin berada dalam tahapan persalinan dan kondisi yang berbeda-beda satu sama lain, sehingga kebutuhan masing-masing pun berbeda. Perawatan yang diberikan perlu disesuaikan dengan kebutuhan masingmasing ibu (IBI, 2006). Peranan petugas kesehatan adalah memantau dengan seksama dan memberikan dukungan serta kenyamanan pada ibu baik segi emosi, perasaan maupun fisik, adapun tindakan yang perlu dilakukan oleh petugas kesehatan haruslah berdasarkan dengan pengetahuan dan standar kesehatan yang dimiliki oleh seorang bidan.

Bidan merupakan salah satu tenaga kesehatan yang memiliki posisi penting dan strategi terutama dalam penurunan Angka Kematian Ibu (AKI) dan Angka Kesakitan dan Kematian Bayi (AKB), bidan memberikan pelayanan yang berkesinambungan dan paripurna, berfokus pada aspek pencegahan, promosi dengan berlandaskan kemitraan dan pemberdayaan masyarakat bersama-sama dengan tenaga kesehatan lainnya untuk senantiasa siap melayani siapa saja yang membutuhkannya, kapan dan dimanapun berada (Kepmenkes RI, 2007).

Menurut ketua Ikatan Bidan Indonesia (IBI) Wastidar Musbir, sebanyak 80\% penduduk Indonesia bermukim di sekitar 69.061 desa. Ikatan Bidan Indonesia mempunyai angggota yang tersebar di seluruh Pelosok Indonesia dengan jumlah sekitar 73.526 orang yang meliputi 30 propinsi dengan 318 cabang dan 1243 ranting, maka diharapkan profesi bidan yang berada dekat dengan masyarakat dapat memberikan pelayanan kesehatan terutama pelayanan persalinan pada ibu (IBI, 2006).

Faktor penyebab tidak langsung kematian ibu dapat disebabkan oleh bidan yang tidak memiliki kemampuan memberikan pelayanan emergensi dalam penanganan pertolongan persalinan, pada Survei demografi kesehatan Indonesia 2002/2003, Angka kematian ibu di Indonesia adalah 307/100.00 Kelahiran hidup (JNPKKR,2008). Di Palembang pada tahun 2007 AKI 11/29.175 atau 38/100.000 kelahiran hidup (Dinkes Kota,2008) jarak yang diinginkan yaitu 265 dan 248/100.000 kelahiran pada tahun 2006/2007. Dan dari semua itu telah disepakati bahwa cakupan pelayanan tenaga kesehatan terlatih adalah kunci dari perbaikan pada status kesehatan ibu (JNPK-KR, 2008). 
Berdasarkan uraian di atas, maka peneliti tertarik untuk melakukan penelitian tentang "Hubungan Pengetahuan, Sikap, dan Tindakan Bidan Terhadap Kepatuhan Pelaksanaan Asuhan Persalinan Kala II di Rumah Bersalin dan Balai Pengobatan UMMI Palembang Tahun 2018".

\section{METODE PENELITIAN}

\section{Jenis Penelitian}

Penelitian ini adalah penelitian akademik yang menggunakan metode observasional dengan rancangan penelitian cross sectional study yang bersifat kuantitatif. Penelitian ini menggunakan uji T-Independent.

\section{Waktu dan Tempat Penelitian}

Penelitian ini dilaksanakan di Rumah Bersalin UMMI Palembang pada bulan April - Mei Tahun 2018.

\section{Target/Subjek Penelitian}

Menurut Sugiyono (2014:118) Teknik sampling jenuh yaitu bila semua anggota populasi digunakan sebagai sample yang memiliki jumlah populasi yang relatif kecil. Sehingga sampel yang digunakan pada penelitian ini berjumlah 15 orang. Sampel yang diambil yaitu seluruh bidan yang membantu proses persalinan di Rumah Bersalin UMMI Palembang Tahun 2018.

\section{Prosedur}

Penelitian ini dilakukan dengan cara pengamatan dan data yang dipakai adalah data primer yaitu data yang didapat dan dikumpulkan oleh peneliti langsung pada saat penelitian. Dimana peneliti menilai langsung kegiatan bidan dalam melakukan asuhan kala II pada ibu bersalin dengan menggunakan checklist dan questioner yang telah dipersiapkan oleh peneliti. Checklist peneliti sendiri yang melihat secara langsung berdasarkan standar pertolongan persalinan sedangkan questioner diisi oleh bidan-bidan yang bekerja di Rumah Bersalin UMMI Palembang Tahun 2018.

\section{Data, Intrumen, dan Teknik Pengumpulan Data}

Penelitian ini dilakukan dengan cara pengamatan dan data yang dipakai adalah data primer yaitu data yang didapat dan dikumpulkan oleh peneliti langsung pada saat penelitian.

Instrument yang dipakai dalam pengumpulan data adalah checklist dan questioner dengan cara observasi.

Dalam penelitian ini yang menjadi variabel dependen adalah "Kepatuhan Akan Pelaksanaan Asuhan Persalinan Kala II".

Sedangkan yang menjadi variabel independen adalah

1. Pengetahuan Bidan Tentang Tindakan Pelaksanaan Asuhan Persalinan Kala II

2. Sikap Bidan Tentang Tindakan Pelaksanaan Asuhan Persalinan Kala II

3. Tindakan Bidan Tentang Kepatuhan Pelaksanaan Asuhan Persalinan Kala II

Setelah Semua lembar checklist dan kuesioner pengetahuan, sikap dan tindakan bidan terhadap kepatuhan dalam penatalaksanaan asuhan persalinan kala II sudah terisi lengkap dan jelas, kemudian dikumpulkan dan diolah kedalam master tabel atau data base computer menggunakan bantuan program SPSS for windows. Data yang telah di entry di periksa kelengkapan dan kebenarannya.

\section{Teknik Analisis Data}

Hasil penelitian diolah dengan menggunakan analisis univariat dan analisis bivariat.

Analisa univariat disajikan dengan menggunakan tabel distribusi frekuensi. Analisa ini dilakukan untuk mengetahui distribusi frekuensi dan prosentase pada variabel bebas ( pengetahuan, sikap dan tindakan ) dan variabel terikat ( kepatuhan pelaksanaan asuhan persalinan kala II ) di Rumah Bersalin dan Balai Pengobatan UMMI Palembang Tahun 2018. 
Analisa bivariat ini dilakukan untuk mengetahui hubungan variabel bebas dengan variabel terikat. Untuk menguji tingkat kemaknaan dilakukan uji TIndependent. Teknik ini digunakan untuk membuktikan hipotesis hubungan dua variabel yaitu :

1. Ho $\neq$ Apabila $p$ value $\leq \alpha(0,05)$ maka Ho ditolak yang artinya ada Hubungan yang bermakna antara Pengetahuan, Sikap dan Tindakan Bidan Terhadap Kepatuhan Pelaksanaan Asuhan Persalinan Kala II.

2. $\mathrm{Ha}=$ Apabila nilai $\mathrm{p}$ value $>\alpha(0,05)$ artinya tidak ada Hubungan yang bermakna antara Pengetahuan, Sikap dan Tindakan Bidan Terhadap Kepatuhan Pelaksanaan Asuhan Persalinan Kala II. Dan dalam Analisis Bivariat ini menggunakan bantuan program SPSS For Windows.

\section{HASIL PENELITIAN DAN}

\section{PEMBAHASAN}

\section{ANALISIS UNIVARIAT}

Analisa ini dilakukan untuk mengetahui distribusi frekuensi dan persentase pada variabel independen (Pengetahuan, Sikap dan Tindakan bidan) dan variabel dependen (Kepatuhan Bidan Terhadap Penatalaksanaan Asuhan Persalinan Kala II) di Rumah Bersalin UMMI Palembang.

Pada variabel pengetahuan, sikap dan tindakan bidan terhadap kepatuhan bidan pada penatalaksanaan asuhan persalinan kala II dapat disimpulkan beberapa kategori yaitu sebagai berikut :
1. Pengetahuan

\begin{tabular}{lllr}
\multicolumn{3}{c}{ Tabel 3} \\
Distribusi & Frekuensi & dan & Prosentase \\
Berdasarkan & Pengetahuan & Bidan di & Rumah \\
Bersalin UMMI Palembang Tahun 2018
\end{tabular}

No Kategori Frekuensi Presentase

\begin{tabular}{lcc} 
& (f) & $(\%)$ \\
\hline $\begin{array}{l}\text { Pengetahu } \\
\text { an Baik }\end{array}$ & 9 & 60,00 \\
\hline $\begin{array}{l}\text { Pengetahu } \\
\text { an Kurang } \\
\text { Baik }\end{array}$ & 6 & 40,00 \\
\hline Total & 15 & 100,00
\end{tabular}

Hasil penelitian diketahui yaitu 9 responden atau $60 \%$ yang memiliki pengetahuan baik dan untuk pengetahuan kurang baik yaitu 6 responden atau $40 \%$ yang memiliki pengetahuan kurang baik.

2. Sikap

Tabel 4

Distribusi Frekuensi dan Prosentase Berdasarkan Sikap Bidan di Rumah Bersalin UMMI Palembang Tahun 2018

\begin{tabular}{cccc} 
No & Kategori & $\begin{array}{c}\text { Frekuensi } \\
(\mathrm{f})\end{array}$ & $\begin{array}{c}\text { Presentase } \\
(\%)\end{array}$ \\
\hline Sikap & 10 & 66,7 \\
Setuju & 10 & 33,3 \\
\hline Sikap & 5 & \\
Tidak & & \\
Setuju & & 100,00
\end{tabular}

Hasil penelitian diketahui yaitu 10 responden atau $66,7 \%$ yang memiliki sikap setuju dan sikap tidak setuju yaitu 5 responden atau $33,3 \%$ yang memiliki pengetahuan kurang baik.

3. Tindakan

Tabel 5

Distribusi Frekuensi dan Prosentase Berdasarkan Tindakan Bidan di Rumah

Bersalin UMMI Palembang Tahun 2018

\begin{tabular}{|c|c|c|c|}
\hline No & Kategori & $\begin{array}{l}\text { Frekuensi } \\
\text { (f) }\end{array}$ & $\begin{array}{c}\text { Presentase } \\
(\%)\end{array}$ \\
\hline & $\begin{array}{c}\text { Tindakan Ya, } \\
\text { Dilakukan }\end{array}$ & 10 & 66,7 \\
\hline & $\begin{array}{c}\text { Tindakan } \\
\text { Tidak } \\
\text { Dilakukan }\end{array}$ & 5 & 33,3 \\
\hline & Total & 15 & 100,00 \\
\hline
\end{tabular}


Hasil penelitian diketahui yaitu 10 responden atau $66,7 \%$ yang melakukan tindakan asuhan persalinan kala II dan yang tidak melakukan yaitu 5 responden atau $33,3 \%$.

4. Kepatuhan Penatalaksanaan asuhan Persalinan Kala II

Tabel 6

Distribusi Frekuensi dan Prosentase

Berdasarkan Kepatuhan Bidan di Rumah

Bersalin UMMI Palembang Tahun 2018

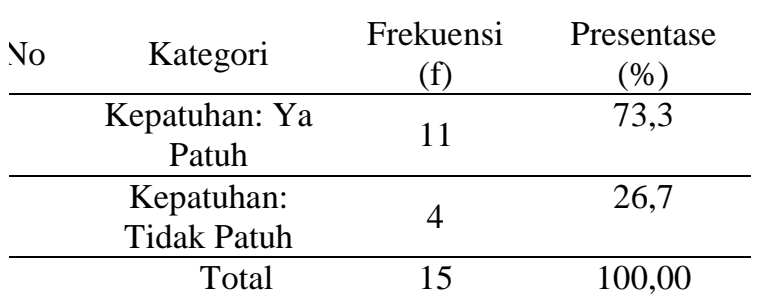

Hasil penelitian diketahui yaitu 11 responden atau $73,3 \%$ yang patuh terhadap penatalaksanaan asuhan persalinan kala II dan yang tidak patuh yaitu 4 responden atau $26,7 \%$.

\section{ANALISIS BIVARIAT}

Sebelum peneliti melakukan uji $\mathrm{T}$ Independent dilakukan uji normalitas data terlebih dahulu. Apabila uji normalitas $\mathrm{p}>$ $\alpha$ (0.05) yang berarti data berdistribusi normal, maka dapat dilakukan uji $\mathrm{T}$ Independent.

1. Analisa Bivariat Hubungan

Pengetahuan Bidan Terhadap

Kepatuhan Penatalaksanaan Asuhan

Persalinan Kala II
Tabel 7

Analisa Bivariat Hubungan Pengetahuan Bidan Terhadap Kepatuhan Bidan Pada

Penatalaksanaan Asuhan Persalinan Kala II di Rumah Bersalin UMMI Palembang Tahun 2018

\begin{tabular}{|c|c|c|c|c|c|c|c|c|}
\hline $\begin{array}{l}\text { Penget } \\
\text { ahuan } \\
\text { Bidan }\end{array}$ & & Mean & $\begin{array}{c}\text { Med } \\
\text { ian }\end{array}$ & SD & $\begin{array}{l}\text { M } \\
\text { in }\end{array}$ & $\begin{array}{l}\mathbf{M} \\
\mathbf{a x}\end{array}$ & $\begin{array}{c}95 \\
\% \mathrm{C} \\
\mathrm{I}\end{array}$ & $\begin{array}{c}\mathbf{P} \\
\text { Value }\end{array}$ \\
\hline Baik & 9 & $\begin{array}{c}84,2 \\
2\end{array}$ & $\begin{array}{c}82,0 \\
0\end{array}$ & $\begin{array}{c}4,52 \\
2\end{array}$ & 80 & 90 & $\begin{array}{c}80,7 \\
5- \\
87.7 \\
0\end{array}$ & \\
\hline $\begin{array}{c}\text { Kurang } \\
\text { Baik }\end{array}$ & 6 & $\begin{array}{c}74,0 \\
0\end{array}$ & $\begin{array}{c}74,0 \\
0\end{array}$ & $\begin{array}{c}3,57 \\
8\end{array}$ & 70 & 78 & $\begin{array}{c}70,2 \\
5- \\
77.7 \\
5\end{array}$ & $\begin{array}{l}0,00 \\
0\end{array}$ \\
\hline
\end{tabular}

Pada pengetahuan baik didapatkan hasil uji normalitas yaitu $\mathrm{P}=0,130(\mathrm{p}>\alpha)$ dan pada pengetahuan kurang baik didapatkan hasil uji normalitas $\mathrm{P}=0,200 \quad(\mathrm{p}>\alpha)$ yang berarti data berdistribusi normal sehingga peneliti dapat melakukan uji T-Independent dan setelah dilakukan uji T-Independent didapatkan nilai rata-rata kepatuhan dengan pengetahuan baik yaitu 84.22 dan pengetahuan kurang baik yaitu 74,00. Dan hasil statistic uji T-Independent didapatkan $\mathrm{P}=0,000(\mathrm{p}<\alpha)$ yang berarti ada hubungan yang bermakna dan signifikan antara pengetahuan bidan terhadap kepatuhan dalam penatalaksanaan asuhan persalinan kala II.

2. Analisa Bivariat Hubungan Sikap Bidan Terhadap Kepatuhan Penatalaksanaan Asuhan Persalinan Kala II

Pada uji normalitas dengan sikap setuju didapatkan nilai $\mathrm{P}=0,200(\mathrm{p}>\alpha)$ dan pada sikap tidak setuju didapatkan nilai $\mathrm{P}=$ $0,200(\mathrm{p}>\alpha)$ Yang berarti data berdistribusi normal, sehingga analisa bivariat bisa dilakukan dengan menggunakan uji statistic T-Independent. 
Tabel 8

Analisa Bivariat Hubungan Sikap Bidan

Terhadap Kepatuhan Bidan Pada

Penatalaksanaan Asuhan Persalinan Kala II di Rumah Bersalin UMMI Palembang Tahun 2018

Hasil statistic uji T-Independent didapatkan nilai rata-rata kepatuhan dengan sikap setuju yaitu 88,30 dan sikap tidak setuju yaitu 74,60 , dan setelah dilakukan uji T-Independent di dapatkan hasil $\mathrm{P}=0,000(\mathrm{p}<\alpha)$ yang berarti ada hubungan yang bermakna dan signifikan antara sikap bidan terhadap kepatuhan penatalaksanaan asuhan persalinan kala II.

3. Analisa Bivariat Hubungan Tindakan Bidan Terhadap Kepatuhan Penatalaksanaan Asuhan Persalinan Kala II

Pada uji normalitas data pada tindakan yang dilakukan didapatkan nilai $\mathrm{P}$ $=0,084(\mathrm{p}>\alpha)$ dan pada tindakan yang tidak dilakukan didapatkan nilai $\mathrm{P}=0,200$ $(p>\alpha)$, Yang berarti data berdistribusi normal, maka analisa bivariat bisa dilakukan dengan menggunakan uji $\mathrm{T}$ Independent.

Tabel 9

Analisa Bivariat Hubungan Tindakan Bidan Terhadap Kepatuhan Bidan Pada Penatalaksanaan Asuhan Persalinan Kala II di Rumah Bersalin UMMI Palembang Tahun 2018

\begin{tabular}{|c|c|c|c|c|c|c|c|c|}
\hline $\begin{array}{l}\text { Tin } \\
\text { dak } \\
\text { an } \\
\text { Bid } \\
\text { an }\end{array}$ & $\mathbf{N}$ & Mean & $\begin{array}{l}\text { Medi } \\
\text { an }\end{array}$ & SD & $\begin{array}{l}\text { M } \\
\text { in }\end{array}$ & $\begin{array}{l}\text { M } \\
\text { ax }\end{array}$ & $\begin{array}{l}95 \\
\% \mathrm{C} \\
\mathrm{I}\end{array}$ & $\begin{array}{c}\mathbf{P} \\
\text { Value }\end{array}$ \\
\hline $\mathrm{Ya}$ & 10 & 89,90 & 90,00 & 3,799 & 85 & 95 & $\begin{array}{l}86,8 \\
0- \\
92.2 \\
0\end{array}$ & \\
\hline Tidak & 5 & 76,40 & 76,00 & 1,517 & 75 & 78 & $\begin{array}{c}74,5 \\
2- \\
78.2 \\
8\end{array}$ & $\begin{array}{l}0,00 \\
0\end{array}$ \\
\hline
\end{tabular}

Hasil uji statistis T-Independent didapatkan nilai rata-rata kepatuhan dengan tindakan yang dilakukan yaitu 89,90 dan tindakan yang tidak dilakukan yaitu 76,40, dan setelah dilakukan uji TIndependent di dapatkan hasil $\mathrm{P}=0,000$ (p $<\alpha$ ) yang berarti ada hubungan yang bermakna dan signifikan antara tindakan bidan terhadap kepatuhan dalam penatalaksanaan asuhan persalinan kala II.

\begin{tabular}{|c|c|c|c|c|c|c|c|c|}
\hline $\begin{array}{l}\text { Sikap } \\
\text { Bidan }\end{array}$ & $\mathbf{N}$ & Mean & $\begin{array}{c}\text { Medi } \\
\text { an }\end{array}$ & SD & $\begin{array}{l}\mathbf{M} \\
\text { in }\end{array}$ & $\begin{array}{l}\mathbf{M} \\
\mathbf{a x}\end{array}$ & $\begin{array}{c}95 \\
\% \mathrm{C} \\
\mathrm{I}\end{array}$ & $\begin{array}{c}\mathbf{P} \\
\text { Value }\end{array}$ \\
\hline Setuju & 10 & 88,30 & 88,00 & 6,001 & 80 & 97 & $\begin{array}{c}84,0 \\
1- \\
92.5 \\
9\end{array}$ & $*$ \\
\hline $\begin{array}{l}\text { Tidak } \\
\text { Setuju }\end{array}$ & 5 & 74,60 & 75,00 & 2,966 & 70 & 78 & $\begin{array}{c}70,9 \\
2- \\
78.2 \\
8\end{array}$ & $\begin{array}{c}0,00 \\
0\end{array}$ \\
\hline
\end{tabular}

\section{KESIMPULAN}

Dari hasil penelitian tentang Hubungan Pengetahuan, Sikap dan Tindakan Bidan Terhadap Kepatuhan Pelaksanaan asuhan persalinan kala II di Rumah Bersalin UMMI Palembang Tahun 2013, maka ditarik kesimpulan bahwa ada hubungan yang bermakna dan signifikan antara pengetahuan, sikap dan tindakan bidan terhadap kepatuhan dalam penatalaksanaan asuhan persalinan kala II dengan hasil uji statistic T-Independent didapatkan

1) $P=0,000(p \leq \alpha)$ yang berarti ada hubungan yang bermakna dan signifikan antara pengetahuan bidan terhadap kepatuhan dalam penatalaksanaan asuhan persalinan kala II.

2) $P=0,000(p \leq \alpha)$ yang berarti ada hubungan yang bermakna dan signifikan antara sikap bidan terhadap kepatuhan penatalaksanaan asuhan persalinan kala II.

3) P $=0,000(p \leq \alpha)$ yang berarti ada hubungan yang bermakna dan signifikan antara tindakan bidan terhadap kepatuhan dalam penatalaksanaan asuhan persalinan kala II.

\section{SARAN}

- Bagi Rumah Bersalin UMMI, diharapkan rumah bersalin UMMI dan instalasi lain dapat meningkatkan 
standar asuhan kebidan khususnya persalinan dengan cara mengikuti pelatihan-pelatihan terutama pelatihan kebidanan serta meningkatkan kemampuan agar tenaga kesehatan khususnya bidan dapat menciptakan keefektifan pelayanan dan asuhan yang berkualitas dalam membimbing pasien.

- Bagi Peneliti Lain, diharapkan dapat mengembangkan lagi penelitianpenelitian yang sejenis sehingga terjadi pengembangan ilmu pengetahuan terutama ilmu pengetahuan tentang asuhan persalinan normal.

\section{UCAPAN TERIMA KASIH}

Penulis mengucapkan terima kasih kepada seluruh pihak yang membantu dan yang telah memberi dukungan terhadap penelitian ini.

\section{DAFTAR PUSTAKA}

Prawirohardjo, Sarwono, Ilmu Kebidanan, 2007, Yayasan Bina Pustaka, Jakarta.

Saswita Rohani, Marisah, Asuhan Kebidanan Pada Masa Persalinan, 2011, Salemba Medika, Jakarta.

Ari Sulistyawati, Nugraheny Esti, Asuhan Kebidanan Pada Ibu Bersalin, 2010, Salemba Medika, Jakarta.

Tim Revisi. Asuhan Persalinan Normal, 2008. Jakarta: JNPK-KR.

Notoatmodjo,Soekidjo.2003.Pendidikan dan Perilaku Kesehatan, Rineka Cipta, Jakarta.

Ircham Machfoedz dan Eko Suryani. Pendidikan Kesehatan dan Promosi Kesehatan. 2004. Yogyakarta :Fitramaya.

Mandar.Polewali:http//www.arali2008.file. wordpress.com.

Salan, Rudy. Perilaku Kesakitan dan Peranan Sakit, 2008. Jakarta:http//www.depkes.go.id.
Churchill, Gilbert A. 2005. "Dasar-Dasar Riset Pemasaran", Edisi 4, JilidI, Alih Bahasa Oleh Andriani, Dkk, Penerbit Erlangga, Jakarta.

Henderson, C., Jones, K. 2006. Buku Ajar Konsep Kebidanan. Jakarta:EGC.

Chapman, Vicky. 2006. Asuhan Kebidanan: Persalinan dan Kelahiran. Cetakan I. Penerjemah: H.Y. Kuncara. Editor Edisi Bahasa Indonesia Monica Ester. Jakarta: EGC.

Manuaba, I.G. 2001. Kapita Selekta Penatalaksanaan Rutin Obstetri Ginekologi dan KB. Jakarta: EGC.

Wiknjosastro, H. 2002. Ilmu Kebidanan. Jakarta: Yayasan Bina Pustaka Sarwono.

Saifuddin, A.B. 2002. Buku Panduan Praktis Pelayanan Kesehatan Maternal dan Neonatal. Jakarta: YBPSP-JNPKKR-POGI-JHPIEG 